\title{
Hybrid and Adaptive P\&O Maximum Power Point Tracking Techniques for PV Generation Systems
}

\author{
Eman Eltahera ${ }^{a}$ Abdel-Raheem Youssef ${ }^{b}$ and Essam E. M. Mohamed ${ }^{b}$ \\ ${ }^{a}$ Upper Egypt Electricity Distribution Company, Luxor, Egypt; \\ ${ }^{b}$ Department of Electrical Engineering, Faculty of Engineering, South Valley University, \\ Qena, Egypt
}

Article History: Received: 10 November 2020; Revised 12 January 2021 Accepted: 27 January 2021; Published online: 5 April 2021

\begin{abstract}
Maximum power point tracking (MPPT) techniques work to track the maximum power from the PV cell. A lot of conventional MPPT techniques, such as the perturb and observe (P\&O), succeed in catch the maximum power point (MPP) with a good performance. However, they suffer many problems during fast varying weather conditions, where slow time response and high oscillations are dominant. Also, it is difficult to select the right direction for new steps. This article illustrates two new $\mathrm{P} \& \mathrm{O}$ MPPT techniques for PV generation systems. They operate on the power-voltage (P-V) curve under different weather conditions. The first is an adaptive perturb and observe (A-PO) technique, which changes the perturbation step-size adeptly to deal with the rapidly varying weather conditions. The second is a hybrid perturb and observe technique (H-PO), which uses a variable step-size according to the location of the operating point relative to the MPP. The MATLAB/SIMULINK software is used to study the truth of the proposed techniques. The results demonstrate that both techniques attain the MPP faster than the conventional techniques and at a reduced oscillation rate.
\end{abstract}

\section{Heading 1: Introduction}

Since antiquated occasions, petroleum derivatives have been the world's principle wellspring of energy, regardless of their adverse consequences, ecological contamination, and being exposed to exhaustion. In ongoing many years, the quest for lasting elective fuel sources has become an overall issue. Environmentally friendly power sources (RES) are the arrangement where they are lasting and maintainable [1].

Among RESs, the photovoltaic (PV) energy change frameworks have an observable effect because of their protected activity, being harmless to the ecosystem, and convenience [2,3]. but, low proficiency is the fundamental disadvantage, where it is in the scope of 9-17\% just [4-6]. As of late, PV innovations have continually advanced in plan and control strategies to expand effectiveness [7]. maximum power point tracking (MPPT) methods have an extraordinary importance to create power from PV system. Where PV age frameworks rely upon climatic conditions. The MPPT is capable to extract most extreme power from the PV system in various climate conditions. Annoy and notice $(\mathrm{P} \& \mathrm{O})$ is perhaps the most utilized MPPT procedures [8-10]. The $\mathrm{P} \& \mathrm{O}$ technique relies upon annoying the progression size and noticing the difference in extricated power until it arrives at the maximum power point (MPP).

The $\mathrm{P} \& \mathrm{O}$ technique chooses a reasonable advance size to improve the PV framework execution. Conventional P\&O (CPO) strategies utilize a fixed advance size, so they have a great deal of disadvantages. In the event that a step with large size is utilized, the speed following reaction is quick, 
yet it fuses high consistent state wavering levels, which diminishes the PV system effectiveness. At the point when a step with little size is utilized, the consistent state swaying levels are diminished, be that as it may, arriving at the MPP is slow, which increasing power losses. Additionally, CPOs lose the correct heading during the quick change in climate conditions, which expands the power losses and lessens the efficiency [11].

To dispose of the blemishes of CPO, a few P\&O MPPT algorithms are proposed. Numerous specialists utilize variable advance size, while others utilize versatile advance size. An adaptive step size $\mathrm{P} \& \mathrm{O}$ algorithm is proposed to conquer the downsides of the CPO. The adaptive control algorithm (ACA) moves the working point nearer to the MPP by multiplying the short-circuit current with an ideal proportionality consistent [8]. The ACA is initiated just if there is an unexpected change in the irradiance or potentially the PV current. The short circuit current is assessed, which lessens the power losses and the extra expense of measuring components. Likewise, it tunes the progression size in two phases, in particular the coarse and fine-tuning. For the coarse-tuning, the perturbation size is resolved dependent on the irradiance level. In any case, for the fine-tuning, the annoyance size is resolved dependent on motions around the working point. An adaptive P\&O MPPT (AD-PO) algorithm is proposed for wind generation systems and tested using realistic wind profiles [12]. The primary highlights of this algorithm are; applying an adaptive ratio to calculate the progression size, and assessing the limits for the particular working areas. The MPPT algorithm [9] is approved by building up an equipment model for unexpected changes in the irradiance. This technique comprises of two algorithms, specifically the current perturbation algorithm (CPA) and the adaptive control algorithm (ACA). The ACA works on case of an unexpected change in radiation or the PV current. These two calculations are inferred dependent on the traditional $\mathrm{P} \& \mathrm{O}$ algorithm and the fragmentary short circuit current algorithm, respectively. The outcomes show that, the proposed calculation is quicker with low oscillation levels than the traditional algorithm.

The adaptive methods proposed by [13] and [14] relies on placing the MPP in the vicinity of the $0.8 \times$ Voc. Thus, the initial search for the MPP is set to $0.65 \times$ Voc. An improved P\&O MPPT method is suggested by [15]. This method is based on feeling the change in both voltage and current $(\Delta \mathrm{V}$ and $\Delta \mathrm{I}$ ), that results from the change of voltage perturbation and irradiation at every step. A predictive $\mathrm{P} \& \mathrm{O}$ MPPT algorithm for fast and reliable tracking of MPP [16]. The proposed method depends on the Least Mean Square (LMS) algorithm. The LMS adaptive filters depends straight on the selection of the factor of the step-size. An improved adaptive P\&O MPPT technique is suggested, the comparison of the proposed method with the traditional adaptive $\mathrm{P} \& \mathrm{O}$ is shown [17]. The proposed $\mathrm{P} \& \mathrm{O}$ method with adaptive duty-cycle perturbation speeds up the dynamic tracking performances, there is still steadystate oscillation around the MPP which may cause continuous dc ripples and affects the reliability of the system. The steady-state MPP determination algorithm is proposed to eliminate the oscillation. The core idea is to compare the difference of two calculated consecutive duty-cycles with a small constant $(\varepsilon<1)$ to determine the current operating conditions. A fast determination of the global maximum operating point (GMOP) under partial shading conditions (PSCs) using a suggested high-speed MPPT module which operates in synchronism with the boost converter [18]. It exploits the inductor characteristic to obtain a PV voltage at maximum power, which acts as a reference for the PI controller to track the GMOP. An improved P\&O methodology was discussed where the duty-cycle was adjusted by the perturbation size [18]-[20]. A variable-step perturb and observe (VS-PO) MPPT method for wind energy conversion system [21]. It is based on dividing the operating area into Multiple sectors. The step-size is depended on the operating section. the Pythagorean theorem and constant voltage CVMPPT are the base equation, which a modified P\&O-MPPT based on. it is presented in [22]. The solar irradiance is divided into two types; slow change $(\Delta \mathrm{G}<10 \mathrm{w} / \mathrm{m} 2)$ and fast change $(\Delta \mathrm{G}>10 \mathrm{w} / \mathrm{m} 2)$. The proposed technique succeeded to solve drawbacks of the conventional PO (CPO-MPPT) algorithm, in addition the output power with CV-MPPT is higher than that of the CPO-MPPT algorithms. 
A variable and adaptive $\mathrm{P} \& \mathrm{O}$ algorithm with current predictive control is suggested [23]. this algorithm depends on the PV array voltage and current sensors. the change of The PV array power variation is slow, in addition remains constant throughout a sampling time to reduce the computational burden. In [24] the authors propose the variable-step perturb and observe (VS-PO) MPPT algorithm for the wind generation system. This method is based on dividing the power-speed $(\mathrm{P}-\omega)$ curve into modular sectors each with a specific step-size. A hybrid MPPT controller is suggested, which integrates the fuzzy logic controller (FLC) and the P\&O MPPT algorithm of a PV under dynamic weather conditions [25]. The FLC is used to select the zone of MPP then the P\&O technique is employed to tracking the MPP accurately. substantially, the FLC was able to harvest only $85 \%$ of the available power. While the P\&O algorithm can achieve high accuracy by using a small step size. A modified P\&O MPPT is suggested, which integrate an Artificial Bee Colony (ABC) algorithm and a $\mathrm{P} \& \mathrm{O}$ algorithm [26]. ABC works in the first stage, then $\mathrm{P} \& \mathrm{O}$ works in the second stage. In the proposed algorithm the global MPP (GMPP) is first tracked by recalling the $\mathrm{ABC}$ algorithm followed by the $\mathrm{P} \& \mathrm{O}$ algorithm for the local MPP (LMPP). Thus, the proposed method works by combining the local search ability of $\mathrm{P} \& \mathrm{O}$ with global search ability of $\mathrm{ABC}$ to produce the duty-cycle for the boost converter. A hybrid intelligent of the optimal global maximum power point tracking (GMPPT) algorithm is proposed for a partial shading PV system [27]. It is depended on an improved particle swarm optimization (PSO) algorithm and variable step perturb and observe $(\mathrm{P} \& \mathrm{O})$ algorithm.

The authors of [19] and [28] suggest the use of multiple variables instead of a single one to extract more power from the photovoltaic system. It works in two stages, the original $\mathrm{P} \& \mathrm{O}$ technique and the multivariable $\mathrm{P} \& \mathrm{O}$ technique. On the other side, this method makes the PV system very complex as compared to other P\&O methods. The authors of [29] and [30] suggest a hybrid P\&O MPPT method, which is used under rapid conditions. This method uses the current perturbation, adaptive perturbation, and the variable perturbation to track the MPP. In [31] a variable step-size P\&O MPPT algorithm is proposed, which is based on dividing the P-V curve into four sectors. Variable step sizes are used based on the sector location of the operating point. When the operating power point is located in the sector near the MPPT, a small step-size is used. On the other side, a large step-size is used. This paper presents two new techniques to improve the performance of the $\mathrm{P} \& \mathrm{O}$ technique. Firstly, a new adaptive perturb and observe (APO) technique is presented. The APO adeptly changes the step-size. The step-size becomes large, when the operating point is far from the MPP, then it is gradually decreased until it reaches the MPP based on the change of the power and voltage. Secondly, a hybrid perturb and observe (HPO) is presented. The HPO is based on dividing the PV curve into two sectors according to the output power relative to the MPPT. The first sector is from 0 to $95 \%$ of the MPPT value. The second sector is from $95 \%$ to $100 \%$ of the MPPT. If the operating point is in the first section, the MPPT control selects a large fixed step-size. Else, if the operating point is in the second section, the MPPT control selects an adaptive step-size.

The PV conversion system is exhibited in Figure 1. The PV system consists of the PV cells, the boost converter, and the grid-side converter. the PV modules are responsible for converting the solar irradiance to electrical energy. The maximum power point tracking control, which is used to catch maximum power point (MPP) by adjusting the DC output voltage to the optimal operating voltage. The grid-side converter is used to deliver energy to the utility grid by developing an AC voltage (synchronized with the grid voltage). The grid-side filter attenuates the AC voltage harmonics. 


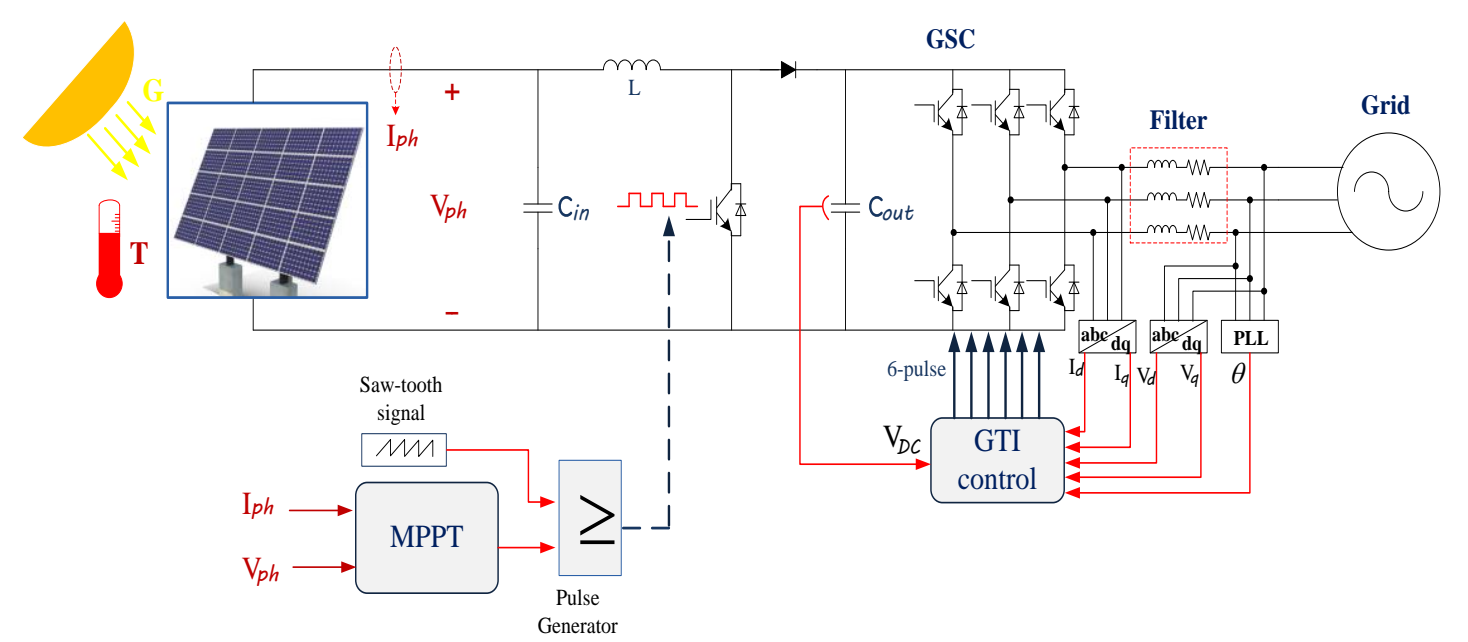

\section{Heading 2: Model of the PV cell}

Figure 1. Studied system

The Photovoltaic cell is the main and key component in the PV systems, it receives the sunlight and transforms it into electric power. Several solar cells are connected in series/parallel to form the solar arrays for obtaining the required power. A PV cell can be represented as a single diode model as shown in Figure 2. The following equation represents the current-voltage relationship of the PV module (1).

$$
\mathrm{I}_{o}=N_{p} I_{p h}-N_{p} I_{r s}\left[e^{\frac{q\left(V+R_{S} \cdot I_{o}\right)}{A \cdot K \cdot T \cdot N_{S}}}-1\right]-N_{p}\left[e^{\frac{q\left(V+R_{S} \cdot I_{O}\right)}{N_{S} \cdot R_{S h}}}\right]
$$

where,

$\mathrm{I}_{\mathrm{o}}$ is the output current.

$V$ is the voltage across the output terminals.

$\mathrm{I}_{\mathrm{ph}}$ is the light-generated current.

$\mathrm{I}_{\mathrm{rs}}$ is the reverse saturation current.

$q$ is the electron charge $\left(1.6 \times 10^{-19} \mathrm{C}\right)$.

$A$ is the $p-n$ ideality factor.

$k$ is the Boltzmann's constant $\left(1.38 \times 10^{-23} \mathrm{~J} / \mathrm{K}\right)$.

$N_{S}$ and $N_{p}$ are the number of series/parallel PV cells, respectively.

This model operates under varying irradiation at a constant temperature. The used module is a Canadian Solar CS5P-220 M and its output characteristics at fixed uniform irradiance $\left(1000 \mathrm{~W} / \mathrm{m}^{2}\right)$ are shown in Table 1.

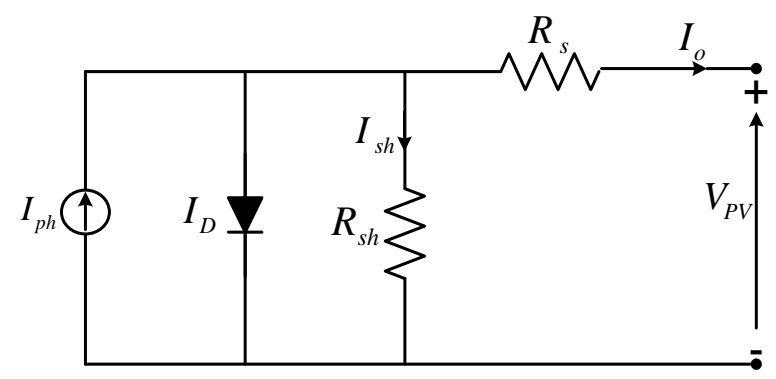

Figure 2. Single module characteristic

Table 1. the used module characteristics

\begin{tabular}{lll}
\hline Parameters & Symbol & Value \\
\hline Maximum power & $\mathrm{P}_{\mathrm{MPP}}$ & $220 \mathrm{~W}$ \\
Voltage at $\mathrm{P}_{\max }$ & $\mathrm{V}_{\mathrm{MPP}}$ & $48.3159 \mathrm{~V}$ \\
Current at $\mathrm{P}_{\max }$ & $\mathrm{I}_{\mathrm{MPP}}$ & $4.54758 \mathrm{~A}$
\end{tabular}




\begin{tabular}{lll} 
Open circuit voltage & $\mathrm{V}_{\mathrm{oc}}$ & $59.2618 \mathrm{~V}$ \\
Short circuit current & $\mathrm{I}_{\mathrm{sc}}$ & $5.09261 \mathrm{~A}$ \\
Temperature, at STC & $\mathrm{T}$ & $25^{\circ} \mathrm{C}$ \\
\hline
\end{tabular}

\section{Heading 3: Conventional PO algorithm}

One of the control units within the PV system is the MPPT algorithm, which is responsible for extracting the maximum power from the PV panels. As the output energy of solar systems depends on weather conditions, which are usually unstable, as shown in Figure 3. CPO relies on the change in the PV generated power as the voltage changes $(\mathrm{dP} / \mathrm{dV})$. If $\mathrm{dP} / \mathrm{dV}>0$, the $\mathrm{PV}$ voltage is altered in the same direction with a constant step-size. Else, the PV voltage is altered in the reverse direction with the same step-size, as shown in Figure 4. The main problem in CPO is its dependency on a fixed step-size, when the little step-size is used as shown in Figure 4(a), low steady-state oscillations are achieved but, it requires a long time to reach the MPP which, increases the power losses. further, when a large step-size is used, as shown in Figure 4(b), the P\&O tracks the MPP faster, however, the steady-state oscillation is high.

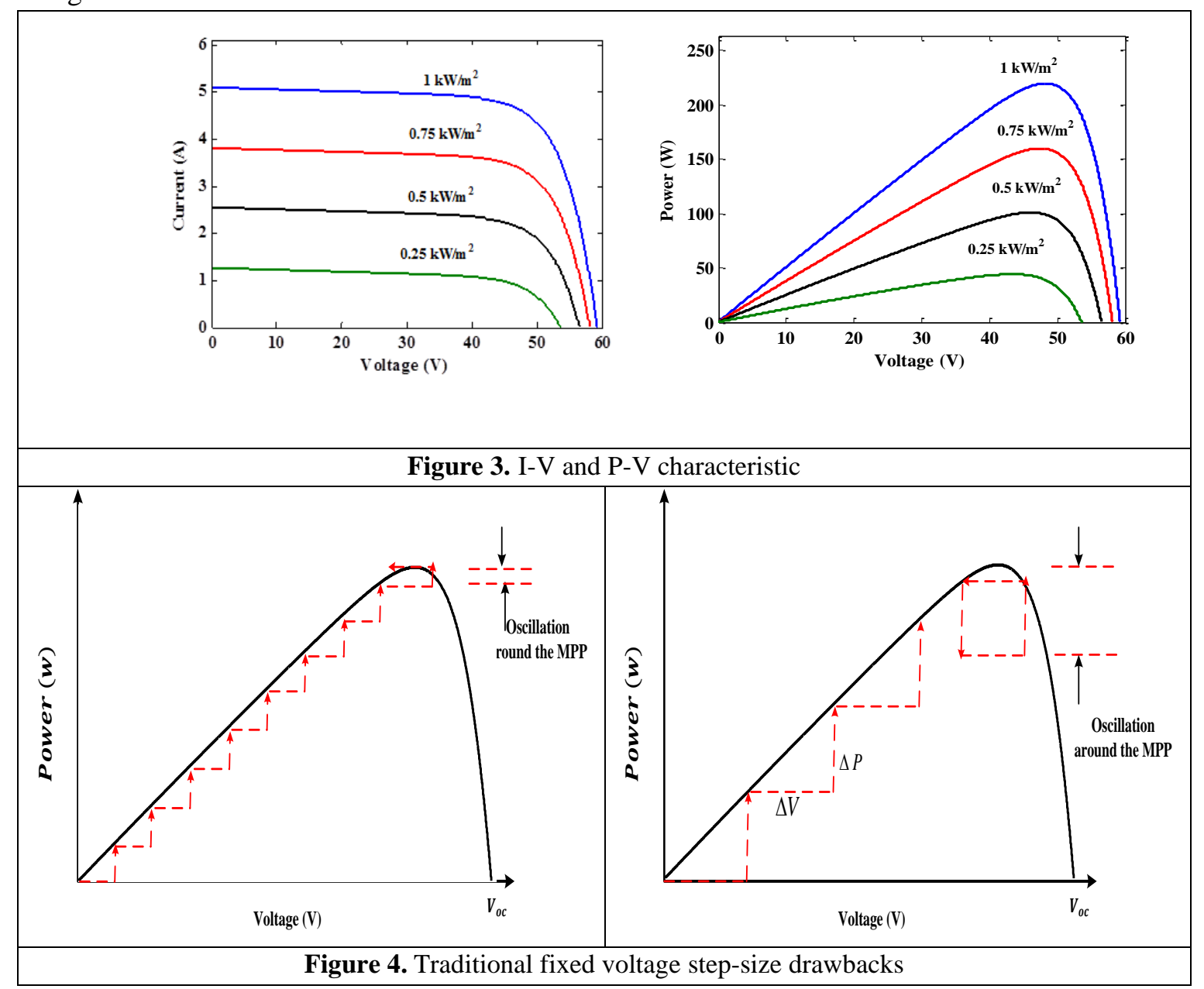

\section{Heading 4: The proposed techniques}

The proposed techniques are divided into two algorithms, the first algorithm is an Adaptive $\mathrm{P} \& \mathrm{O}$ maximum power point tracking technique (A-PO), which depends on a dynamic step-size to catch the MPP. The second algorithm is the hybrid $\mathrm{P} \& \mathrm{O}$ maximum power point tracking technique (H-PO), which depends on varying step-size.

- The A-PO algorithm 
The A-PO works on an Adaptive step-size (AS-S), which varies dynamically. When the operating point is far of the MPP, the AS-S becomes large, then it continuously declines until reaching the required MPP. The AS-S ensures quick response time and low oscillations level around MPP. This technique works on a dynamic step-size, which is selected by the ratio between the changes of power and voltage $(\mathrm{dP} / \mathrm{dV})$. The following equation represents the AS-S of the adaptive perturb and observe the MPPT technique (A-PO) (2) :

$$
\beta=M \log _{10}\left|\frac{\Delta P}{\Delta V}\right|
$$

where,

$\beta$ is the dynamic step-size.

$\Delta \mathrm{P}$ and $\Delta \mathrm{V}$ are the power and voltage changing, respectively.

$\mathrm{M}$ is a constant that requires tuning.

Equation ( 2 ) is used to reduce the perturbation step-size. This achieves Improvement in a steady-state and a dynamic performance as shown in Figure 5.

The flow-chart of the A-PO technique is shown in Figure 6. When applying the A-PO technique it demonstrates its ability to work under ever-changing irradiance and to reach the best working area to extract the maximum power from the solar energy generation system. It shows responsive speed while ensuring very little fluctuation level around the MPP.

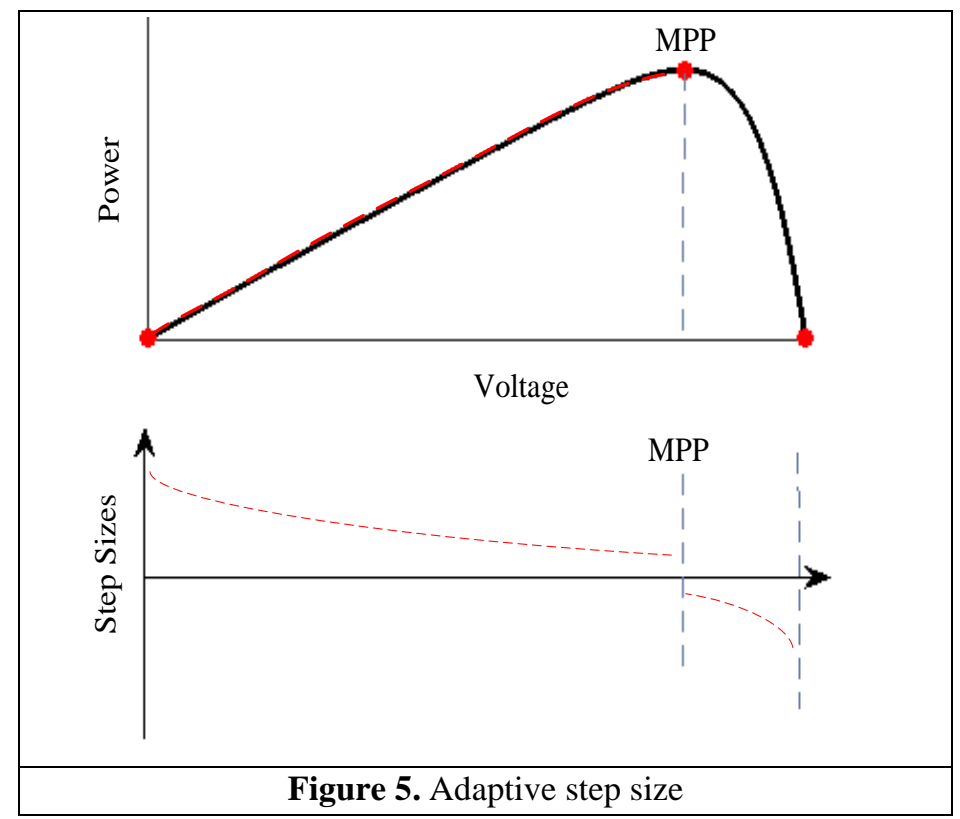




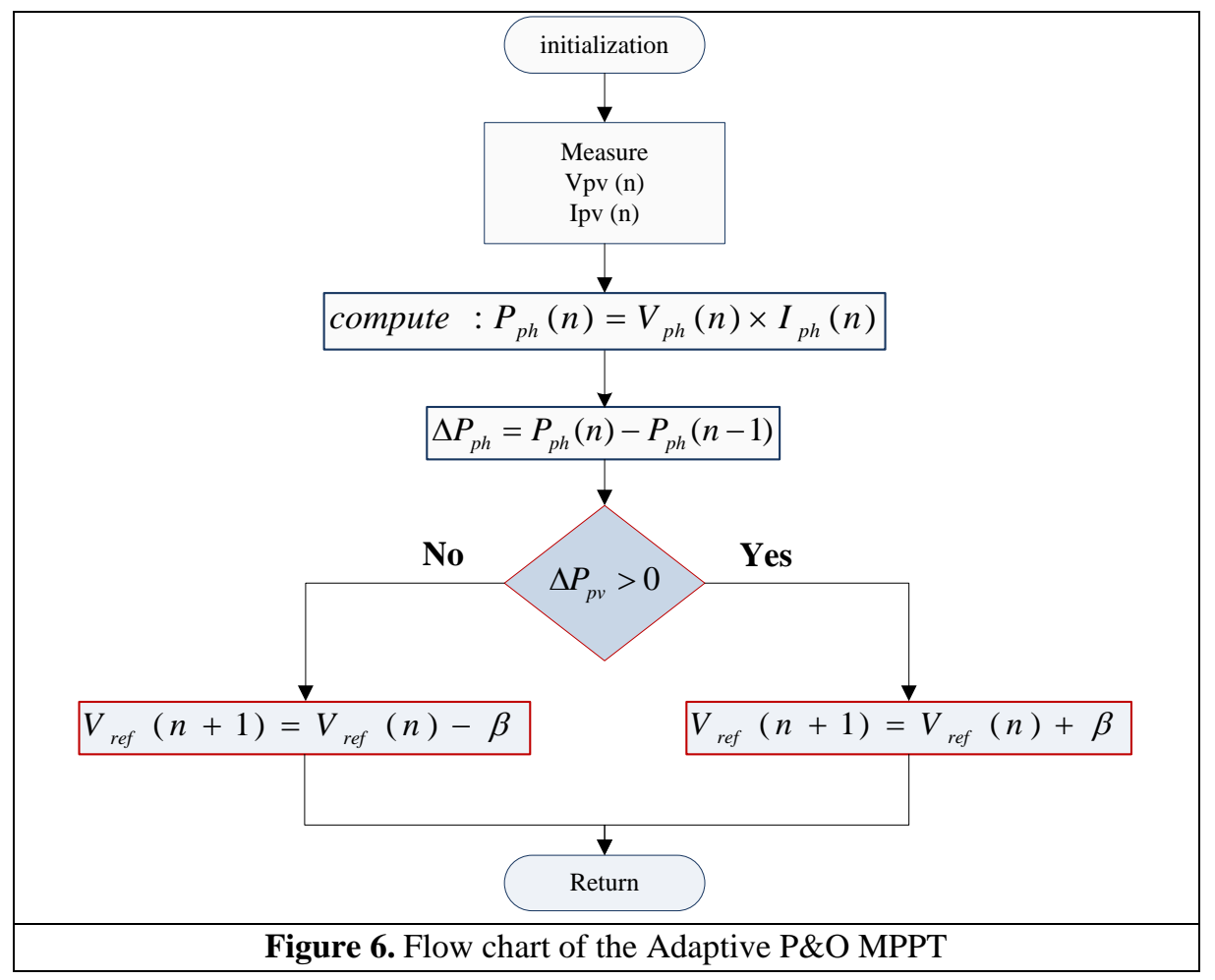

- $\quad$ The H-PO algorithm

The H-PO combines two techniques, the previous adaptive technique (A-PO) and the conventional $\mathrm{P} \& \mathrm{O}$ technique (CPO) with a fixed step-size (F-SS). Where the CPO technique guarantees the speed of response, while the A-PO technique with an adaptive step-size (A-SS) guarantees a low level of oscillation around the MPP. The H-PO technique is based on comparing the actual power to the maximum power value, as the $\mathrm{P}-\mathrm{V}$ curve is divided into areas according to the power value as shown in Figure 7. As the actual value of the power is compared to $95 \%$ of the maximum energy value, this resulted in dividing the curve into 4 sectors. If the actual point is less than $0.95 \times \mathrm{P}_{\max }$, it's far away from the MPP, then it is in Sector (1) or Sector (4), and the F-SS is used. If the actual point is higher than $0.95 \times \mathrm{P}_{\max }$, i.e. it is close to the MPP, it is located in Sector (1) or Sector (3) then the A-SS is used.

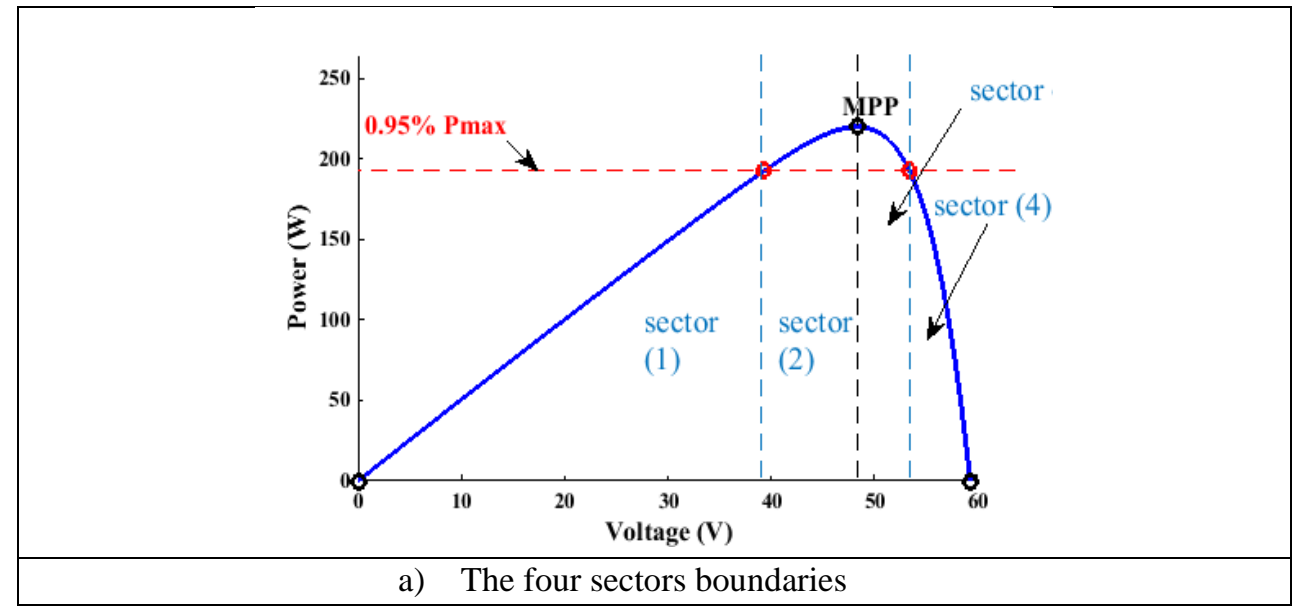




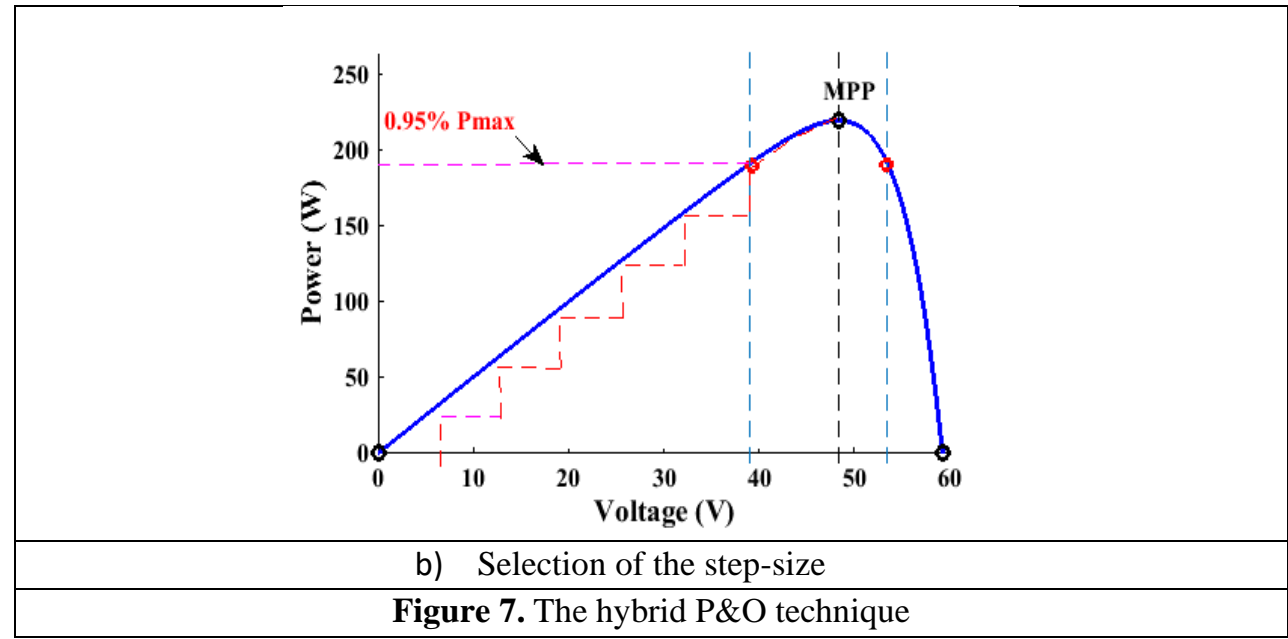

The flow chart of the hybrid $\mathrm{P} \& \mathrm{O}$ technique is depicted in Figure 8. The large oscillations around the MPP are reduced by using the adaptive step-size, beside enhancing the time response by using the fixed large step-size. Thus, the second proposed technique operates good under changing radiation rates. The various step-sizes are the fixed step $\left(\alpha=1 \mathrm{e}^{-4}\right)$ and an adaptive step size $(\beta)$.

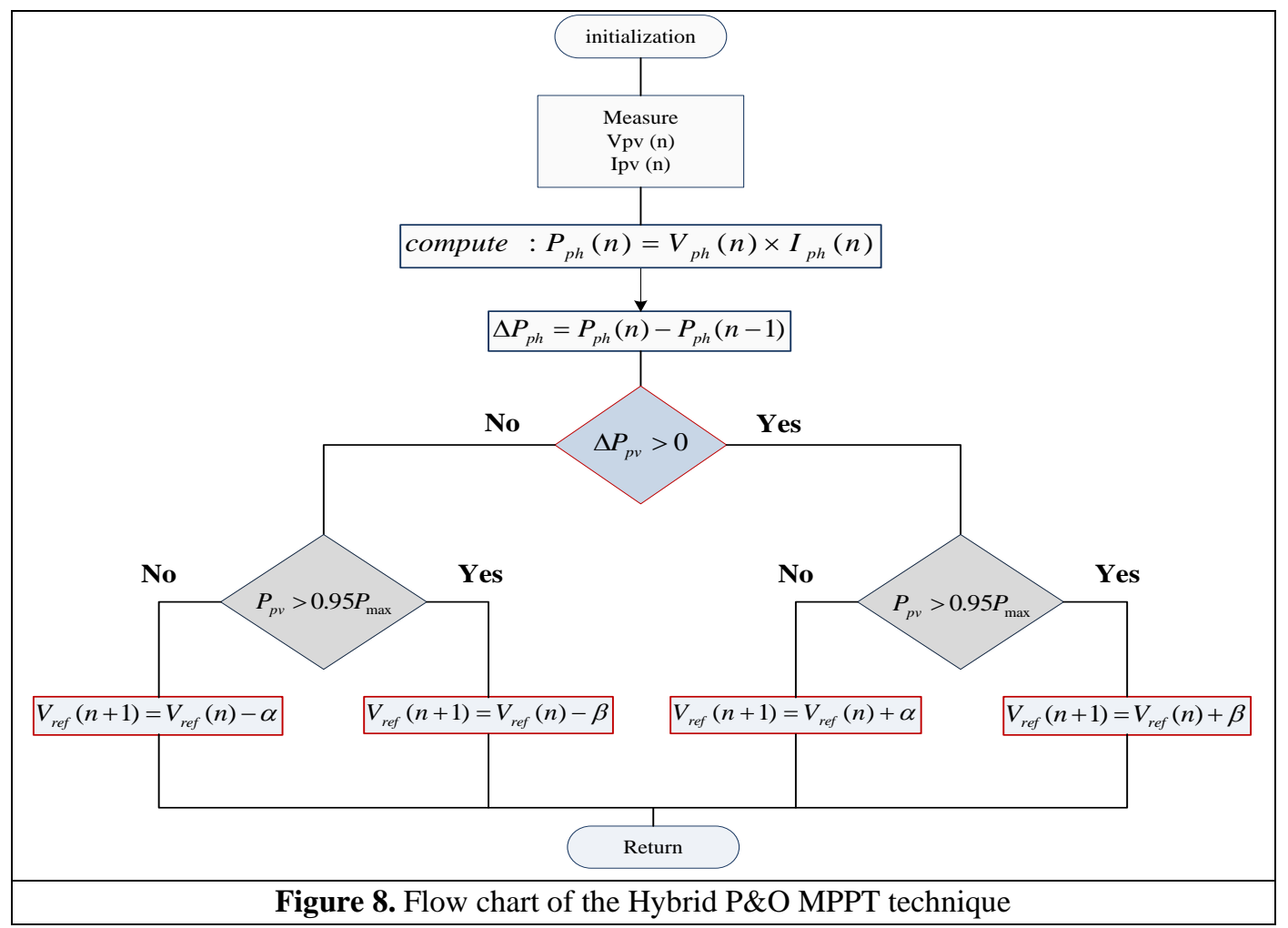

\section{Heading 4: Simulation results}

The Adaptive $\mathrm{P} \& \mathrm{O}$ technique (A-PO) is applied to increase the efficiency of the PV system under the variable irradiation conditions, then the Hybrid $\mathrm{P} \& \mathrm{O}$ technique (H-PO) is applied, which combines the A-PO technique and the conventional $\mathrm{P} \& \mathrm{O}$ technique (CPO) with fixed large step-size. The H-PO technique succeeded in modifying and improvement the efficiency of the PV system. The MATLAB/SIMULINK is used to demonstrate the validity of each of the two suggested techniques, under varying solar radiation. The simulation model determines the effectiveness of the proposed algorithms using a solar irradiance profile with different ramp slopes [30]. When studying the 
performance of the A-PO technique, it can reach the maximum distinct power with a faster response time as well as a low fluctuation level compared with the traditional $\mathrm{P} \& \mathrm{O}$ technique, as is shown in Figure 9.

When studying the performance of the H-PO technique, it also shows good performance, as shown in Figure 10. Finally, the performance of both techniques is compared, which shows improved the performance of the H-PO compared with the A-PO, as is shown in Figure 11.

compare the performance of the conventional $\mathrm{PO}$ with the proposed techniques (A-PO and H-PO) is shown in Table 2. The CPO with a large step-size has large oscillation levels (the ripple voltage is $\sim 8$ V). In contrast, The CPO with a small step-size has small oscillation levels (the ripple voltage equal $\sim 3$ $\mathrm{V}$ ), but its response time is large (settling time is $100 \mathrm{~ms}$ ). The CPO Defects are avoided by the proposed techniques, where the A-PO and $\mathrm{H}-\mathrm{PO}$ have small oscillation levels (the ripple voltage equal $\sim 3 \mathrm{~V}$ ). When comparing the A-PO and $\mathrm{H}-\mathrm{PO}$, the $\mathrm{H}-\mathrm{PO}$ is faster to respond than the A-PO (the settling time is $4 \mathrm{~ms}$ and $20 \mathrm{~ms}$ for the H-PO and A-PO, respectively). The tracking efficiency (Eff ) is calculated by equation (3), where PA is the actual PV power and PT is the theoretical PV power. The proposed techniques succeeded to increase the tracking efficiency, as given in Table 2. Also, the H-PO MPPT exhibits the highest efficiency of $99.63 \%$.

$$
E f f=\frac{\int_{0}^{t} P_{A}}{\int_{0}^{t} P_{T}} \times 100 \%
$$

Table 2. Comparison of the different the P\&O MPPT techniques

\begin{tabular}{|c|c|c|c|c|}
\hline Technique & Ripple voltage (P-P) (V) & Step-size (V) & Settling time (ms) & Efficiency (\%) \\
\hline LS-PO & 8 & $\Delta \mathrm{V}_{1}=1 \mathrm{e}^{-4}$ & 4 & - \\
\hline SS-PO & 3 & $\Delta \mathrm{V}_{2}=1 \mathrm{e}^{-6}$ & 100 & 97.91 \\
\hline A-PO & 3 & $\beta=\mathrm{M} \log _{10}\left|\frac{\Delta \mathrm{P}}{\Delta \mathrm{V}}\right|$ & 20 & 99.35 \\
\hline H-PO & 3 & $\begin{array}{l}\alpha=1 e^{-4} \\
\beta=\mathrm{M} \log _{10}\left|\frac{\Delta \mathrm{P}}{\Delta \mathrm{V}}\right|\end{array}$ & 4 & 99.63 \\
\hline
\end{tabular}




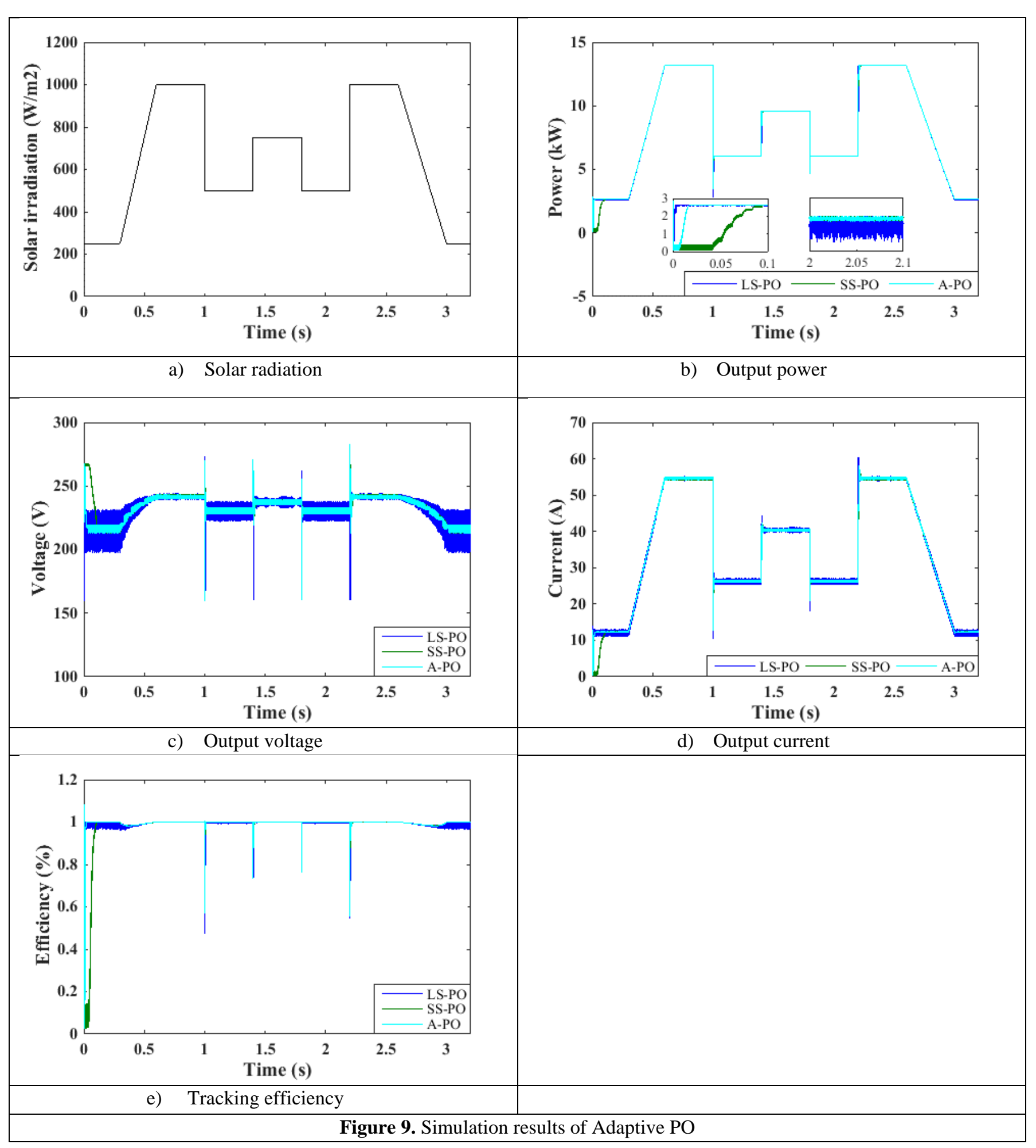




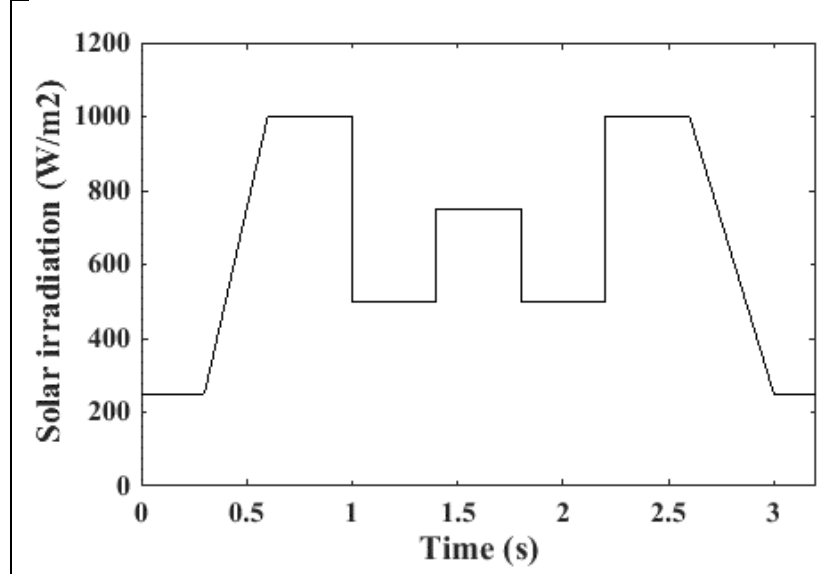

a) Solar radiation

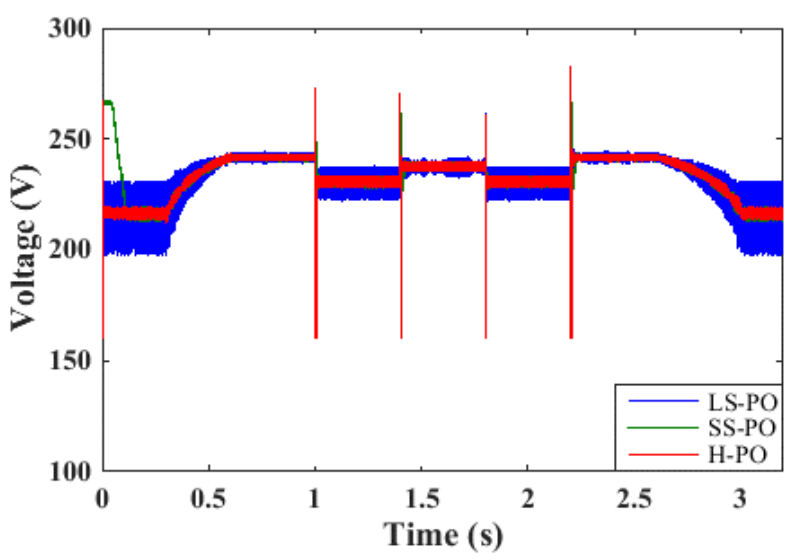

c) Output voltage

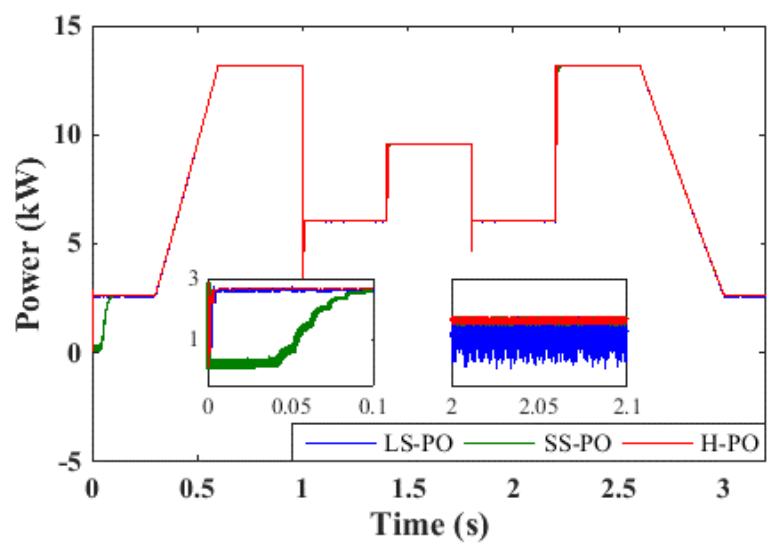

b) Output power

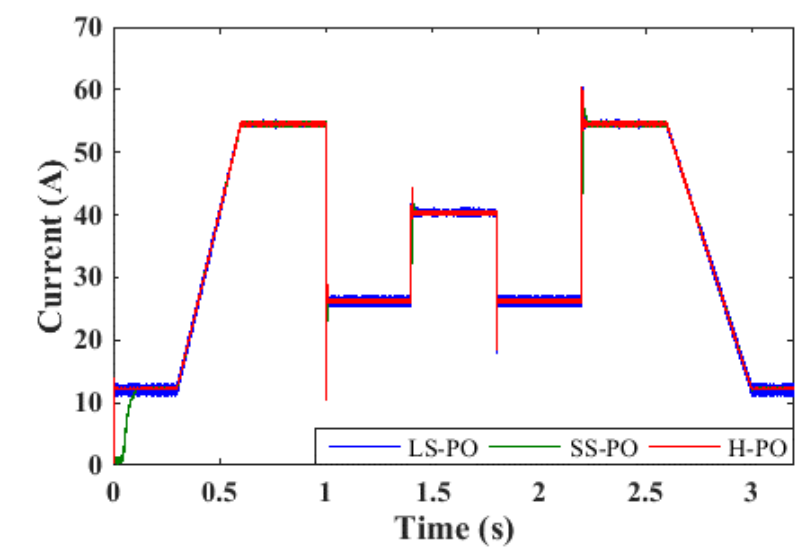

d) Output current

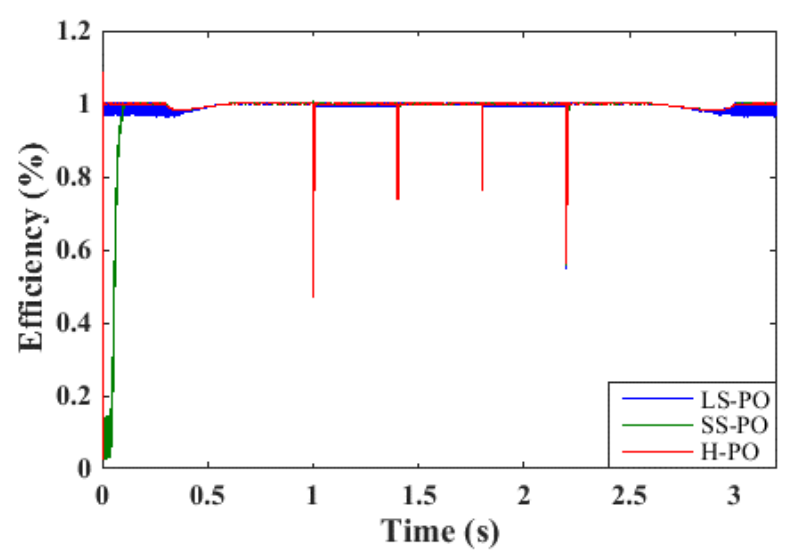

e) Tracking efficiency 


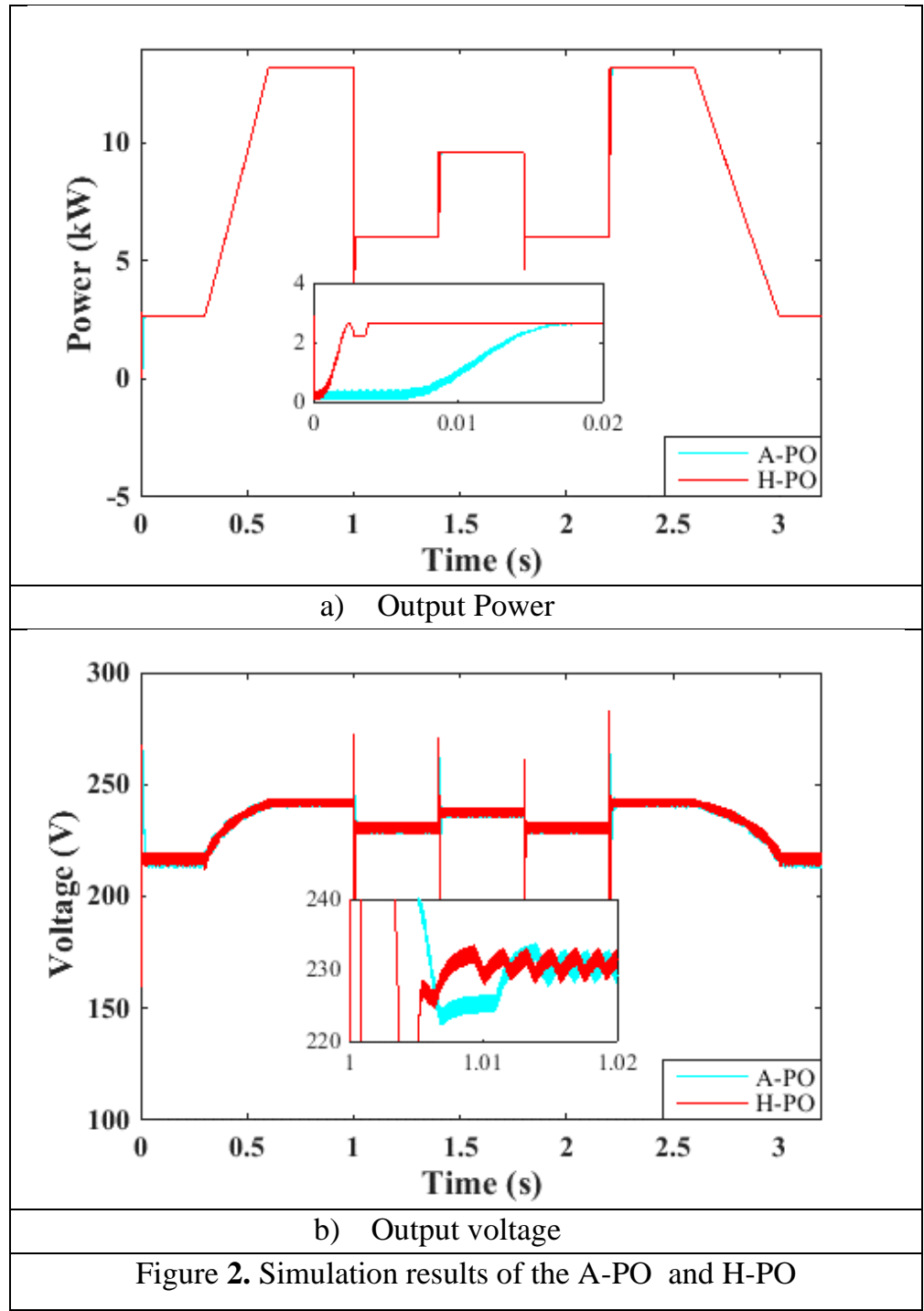

\section{Heading 4: Conclusion}

In this paper, two techniques are proposed, to solve problems of the traditional perturb and observe techniques. First, an Adaptive PO technique is proposed, which uses a dynamic step-size algorithm. Second, a Hybrid PO technique is proposed, that depends on dividing the P-V curve according to the location of the maximum power point. While the H-PO uses a variable step-size. By using the MATLAB/SIMULINK software, the A-PO shows a faster response to track the MPP with low steadystate oscillation levels, compared with the CPO. Lastly, the A-PO and the H-PO are compared. The HPO Speeds up the system response and reduces the steady-state oscillations around MPP, which increase the system efficiency.

\section{References}

[1] J. M. Carrasco et al., "Power-electronic systems for the grid integration of renewable energy sources: A survey," IEEE Trans. Ind. Electron., vol. 53, no. 4, pp. 1002-1016, 2006.

[2] S. Mekhilef, R. Saidur, and A. Safari, "A review on solar energy use in industries," Renew. Sustain. energy Rev., vol. 15, no. 4, pp. 1777-1790, 2011, doi: 10.1016/j.rser.2010.12.018.

[3] K. H. Solangi, M. R. Islam, R. Saidur, N. A. Rahim, and H. Fayaz, "A review on global solar energy policy,” Renew. Sustain. energy Rev., vol. 15, no. 4, pp. 2149-2163, 2011. 
[4] A. Belkaid, J.-P. Gaubert, A. Gherbi, and L. Rahmani, "Maximum power point tracking for photovoltaic systems with boost converter sliding mode control," in 2014 IEEE 23rd International Symposium on Industrial Electronics (ISIE), 2014, pp. 556-561.

[5] D. C. Huynh and M. W. Dunnigan, "Development and comparison of an improved incremental conductance algorithm for tracking the MPP of a solar PV panel," IEEE Trans. Sustain. energy, vol. 7, no. 4, pp. 1421-1429, 2016.

[6] R. Faranda and S. Leva, "Energy comparison of MPPT techniques for PV Systems," WSEAS Trans. power Syst., vol. 3, no. 6, pp. 446-455, 2008.

[7] A. R. Jordehi, "Maximum power point tracking in photovoltaic (PV) systems: A review of different approaches," Renew. Sustain. Energy Rev., vol. 65, pp. 1127-1138, 2016.

[8] S. K. Kollimalla and M. K. Mishra, "Variable perturbation size adaptive P\&O MPPT algorithm for sudden changes in irradiance," IEEE Trans. Sustain. Energy, vol. 5, no. 3, pp. 718-728, 2014.

[9] S. K. Kollimalla and M. K. Mishra, "A novel adaptive P\&O MPPT algorithm considering sudden changes in the irradiance," IEEE Trans. Energy Convers., vol. 29, no. 3, pp. 602-610, 2014.

[10] F. Zhang, K. Thanapalan, A. Procter, S. Carr, and J. Maddy, "Adaptive hybrid maximum power point tracking method for a photovoltaic system," IEEE Trans. Energy Convers., vol. 28, no. 2, pp. 353-360, 2013.

[11] T. Bennett, A. Zilouchian, and R. Messenger, "A proposed maximum power point tracking algorithm based on a new testing standard," Sol. energy, vol. 89, pp. 23-41, 2013.

[12] H. H. H. Mousa, A.-R. Youssef, and E. E. M. Mohamed, "Adaptive P\&O MPPT algorithm based wind generation system using realistic wind fluctuations," Int. J. Electr. Power Energy Syst., vol. 112, pp. 294-308, 2019.

[13] J. Ahmed and Z. Salam, "An Enhanced Adaptive P\&O MPPT for Fast and Efficient Tracking Under Varying Environmental Conditions," IEEE Trans. Sustain. Energy, vol. 9, no. 3, pp. 14871496, 2018, doi: 10.1109/TSTE.2018.2791968.

[14] J. Ahmed and Z. Salam, "A modified P and O maximum power point tracking method with reduced steady-state oscillation and improved tracking efficiency," IEEE Trans. Sustain. Energy, vol. 7, no. 4, pp. 1506-1515, 2016, doi: 10.1109/TSTE.2016.2568043.

[15] M. Abdel-Salam, M.-T. El-Mohandes, and M. Goda, "An improved perturb-and-observe based MPPT method for PV systems under varying irradiation levels," Sol. Energy, vol. 171, pp. 547$561,2018$.

[16] O. Lodin, I. Kaur, and H. Kaur, "Predictive-P\&O Mppt Algorithm for Fast and Reliable Tracking of Maximum Power Point in Solar Energy Systems."

[17] S. Xiao and R. S. Balog, "An improved adaptive perturb \& observe maximum power point tracking technique," in 2018 IEEE Texas power and energy conference (TPEC), 2018, pp. 1-6.

[18] S. Selvakumar, M. Madhusmita, C. Koodalsamy, S. P. Simon, and Y. R. Sood, "High-speed maximum power point tracking module for PV systems," IEEE Trans. Ind. Electron., vol. 66, no. 2, pp. 1119-1129, 2018.

[19] K. L. Lian, J. H. Jhang, and I. S. Tian, "A maximum power point tracking method based on perturb-and-observe combined with particle swarm optimization," IEEE J. photovoltaics, vol. 4, no. 2, pp. 626-633, 2014.

[20] F. Liu, Y. Kang, Y. Zhang, and S. Duan, "Comparison of P\&O and hill climbing MPPT methods for grid-connected PV converter," in 2008 3rd IEEE Conference on Industrial Electronics and Applications, 2008, pp. 804-807.

[21] A.-R. Youssef, A. I. M. Ali, M. S. R. Saeed, and E. E. M. Mohamed, "Advanced multi-sector $\mathrm{P} \& \mathrm{O}$ maximum power point tracking technique for wind energy conversion system," Int. J. Electr. Power Energy Syst., vol. 107, pp. 89-97, 2019. 
[22] S. D. Al-Majidi, M. F. Abbod, and H. S. Al-Raweshidy, "A Modified P\&O-MPPT based on Pythagorean Theorem and CV-MPPT for PV Systems," in 2018 53rd International Universities Power Engineering Conference (UPEC), 2018, pp. 1-6.

[23] Y. Yang and H. Wen, "Adaptive perturb and observe maximum power point tracking with current predictive and decoupled power control for grid-connected photovoltaic inverters," J. Mod. Power Syst. Clean Energy, vol. 7, no. 2, pp. 422-432, 2019.

[24] H. H. H. Mousa, A.-R. Youssef, and E. E. M. Mohamed, "Variable step size P\&O MPPT algorithm for optimal power extraction of multi-phase PMSG based wind generation system," Int. J. Electr. Power Energy Syst., vol. 108, pp. 218-231, 2019.

[25] K. Bataineh and N. Eid, "A hybrid maximum power point tracking method for photovoltaic systems for dynamic weather conditions," Resources, vol. 7, no. 4, p. 68, 2018.

[26] D. Pilakkat and S. Kanthalakshmi, "An improved P\&O algorithm integrated with artificial bee colony for photovoltaic systems under partial shading conditions," Sol. Energy, vol. 178, pp. 3747, 2019.

[27] M. Mao et al., "A hybrid intelligent GMPPT algorithm for partial shading PV system," Control Eng. Pract., vol. 83, pp. 108-115, 2019.

[28] S. Saravanan and N. R. Babu, "Maximum power point tracking algorithms for photovoltaic system-A review," Renew. Sustain. Energy Rev., vol. 57, pp. 192-204, 2016.

[29] S. Amin, S. Khan, and A. Qayoom, "Comparative analysis about the study of maximum power point tracking algorithms: A review," in 2018 International Conference on Computing, Mathematics and Engineering Technologies (iCoMET), 2018, pp. 1-8.

[30] A. K. Abdelsalam, A. M. Massoud, S. Ahmed, and P. N. Enjeti, "High-performance adaptive perturb and observe MPPT technique for photovoltaic-based microgrids," IEEE Trans. power Electron., vol. 26, no. 4, pp. 1010-1021, 2011.

[31] A. I. M. Ali, M. A. Sayed, and E. E. M. Mohamed, "Modified efficient perturb and observe maximum power point tracking technique for grid-tied PV system," Int. J. Electr. Power Energy Syst., vol. 99, pp. 192-202, 2018. 